\title{
Revelação do Diagnóstico da Infecção pelo HIV no Contexto do Aconselhamento: A Versão do Usuário
}

\author{
Diva Maria Faleiros Camargo Moreno ${ }^{1}$ \\ Coordenadora de Unidade Básica de Saúde da Secretaria Municipal da Saúde de São Paulo \\ Faculdade de Saúde Pública da Universidade de São Paulo, São Paulo, Brasil
}

Alberto Olavo Advíncula Reis

Faculdade de Saúde Pública da Universidade de São Paulo, São Paulo, Brasil

\begin{abstract}
Resumo
A partir de uma investigação realizada em dois Centros de Testagem e Aconselhamento em DST/Aids de São Paulo, objetiva-se descrever processos de revelação do diagnóstico da infecção pelo HIV no contexto do aconselhamento sorológico. O estudo envolveu 14 sujeitos entrevistados após a revelação do resultado do teste. Conceitos da teoria psicanalítica de D. W. Winnicott foram utilizados para analisar e compreender os processos de aconselhamento investigados. Os resultados mostraram que o enfrentamento do diagnóstico da infecção pelo HIV e o desejo de cuidar da saúde a partir da revelação do resultado reagente têm efeitos variados nos sujeitos, dependendo do modo como o aconselhamento é feito. De um lado, pode-se ter a oportunidade de confronto consigo mesmo, com os próprios problemas, com a angústia gerada pela revelação do resultado, observando-se maior ou menor integridade psíquica dos sujeitos. Em contraste, isso não foi observado nos casos em que os sujeitos não se sentiram acolhidos e apoiados no aconselhamento. É importante que seja estabelecida uma relação intersubjetiva de ajuda no momento da revelação do diagnóstico da infecção pelo HIV para que o aconselhamento possa cumprir sua função estratégica de focar no problema específico e nos recursos mais saudáveis do indivíduo.
\end{abstract}

Palavras-chave: Aconselhamento, revelação, teoria psicanalítica, sorodiagnóstico do HIV.

\section{Disclosure of the HIV Infection Diagnosis in the Context of Counseling from the User's Perspective}

\begin{abstract}
The present study emerged from a research done in two Testing and Couseling Centers for STD/AIDS in São Paulo. It aims at describing the reagent HIV test disclosure processes within the context of the serological counseling. The study involved 14 subjects interviewed after they were disclosed their test results. In the analysis and understanding of the counseling processes investigated, concepts from D. W. Winnicott's psychoanalytical theory were applied. The results showed that facing the HIV infection diagnosis and being willing to take care of one's health after the reagent result disclosure have different effects on the subjects, depending on how the counseling takes place. From one side, they can have the opportunity to confront themselves, their own problems and the anguish generated by the result disclosure, observing more or less psychic integrity from the subjects. On the other hand, this was not observed in cases where the subjects did not feel welcome and supported during counseling. It is important that an intersubjective relationship of support be established on the moment of the reagent HIV result
\end{abstract}

Endereço para correspondência: Praça Baronesa de Bocaina, 83. Sumarezinho. São Paulo. SP. Brasil. CEP: 05440-030. E-mail: dmfcm@usp.bre albereis@usp.br 
disclosure so that the counseling can fulfill its strategic function to focus on the specific problem and the healthiest resources from the individual.

Keywords: Counseling, disclosure, psychoanalytical theory, HIV serodiagnosis.

\section{La Revelación del Diagnóstico de la Infección por el VIH en el Contexto del Asesoramiento: La Versión del Usuario}

\section{Resumen}

El estudio surge de una investigación que se produjo en dos Centros de Pruebas y Asesoramiento en DST/Sida en São Paulo, con el objetivo de describir procesos de revelación del resultado de la infección por el VIH en el contexto del asesoramiento serológico. El estudio involucró a 14 sujetos a quienes se les hizo una entrevista tras la revelación del resultado del examen. El análisis y la comprensión se hicieron aplicando conceptos de la teoría psicoanalítica de D. W. Winnicott. Los resultados demostraron que hacer frente al diagnóstico de la infección por el VIH y el deseo de cuidar la salud tras la revelación del resultado reactivo tiene efectos distintos en los sujetos, y dependen del modo con el que se hace el asesoramiento. Por un lado, es posible que haya oportunidad del confronto consigo mismo, con los propios problemas, con la angustia generada por la revelación del resultado, observándose más o menos la integridad psíquica de los sujetos. Por otro lado, esto no se observó en los casos en que los sujetos no se sintieron acogidos y apoyados en el asesoramiento. Es importante que se establezca una relación intersubjetiva de ayuda en el momento de la revelación de la infección por el VIH para que el asesoramiento cumpla su función estratégica de enfocar en el problema específico y en los recursos más sanos del indivíduo.

Palabras clave: Asesoramiento, revelación, teoría psicoanalítica, serodiagnóstico del SIDA.

Este estudo tem por propósito descrever processos de revelação do diagnóstico da infecção pelo $H I V$ no contexto do aconselhamento sorológico, a partir da versão do usuário e tomando como referencial teórico de análise a teoria psicanalítica de $\mathrm{D}$. W. Winnicott.

A construção da prática do aconselhamento nos serviços denominados Centros de Testagem e Aconselhamento (CTA) em DST/Aids atuais foi apoiada na teoria de Carl Rogers. Para o autor, . . . a consulta psicológica [counseling] eficaz consiste numa relação permissiva, estruturada de uma forma definida que permite ao paciente alcançar uma compreensão de si mesmo num grau que o capacita a progredir à luz da sua nova orientação (Rogers, 1974a, p. 29).

Em documentos oficiais brasileiros, o aconselhamento é explicitado como técnica preconizada para o trabalho em centros de testagem do HIV. Nesses documentos encontram-se referências quanto ao modo de trabalhar de Rogers e de suas concepções teóricas em torno desta prática (Ministério da Saúde, 1999a, 1999b).
Rogers (1974b) recomenda uma atitude $a u$ têntica do profissional que assume esta tarefa de fazer o aconselhamento, apontando como finalidade desta prática ajudar a pessoa a se integrar, tornar-se independente e amadurecida para resolver seus problemas conforme eles vão aparecendo na sua vida. $\mathrm{O}$ autor parte do princípio que as pessoas têm, em potencial, essa capacidade, podendo chegar, por si mesmas à resolução de suas dificuldades no processo de aconselhamento, desde que lhes seja oferecida uma atmosfera adequada (Rogers, 1974b).

Para alcançar esse objetivo, o aconselhador deve buscar aceitar e compreender a personalidade do usuário, com seus aspectos positivos e negativos, havendo a exigência de uma atitude de aproximação para pensar conjuntamente com ele. Priorizam-se, portanto, na relação envolvida entre aconselhador e usuário, os conteúdos emocionais mais do que os intelectuais e, mais do que resolver um problema, habilitar o usuário a tomar suas decisões no presente e no futuro. Isso é desafiador no aconselhamento em DST/ HIV/Aids, pois este pressupõe uma quantidade 
de informações a serem transmitidas e ainda assim, manter o foco no usuário. Souza, Czeresnia e Natividade (2008) apontam que esse aspecto do aconselhamento o constitui como uma prática paradoxal, na medida em que ele encerra, sob o olhar dos usuários, momentos geradores de acolhimento-tensionamento; diálogo-normatividade; amedrontamento-motivação, reflexãoparalisia.

No aconselhamento em HIV/Aids, devemse criar condições para prover atitude de escuta, respeitar o sistema de crenças dos indivíduos, e contribuir para que eles tenham confiança nos próprios recursos internos para tomar suas decisões de vida. A tarefa adicional consiste em que tudo isto se passa no contexto relacionado a ter ou não ter se infectado pelo Vírus da Imunodeficiência Humana (HIV), ter ou não ter condições de adotar práticas sexuais mais protegidas, poder ou não poder negociar o uso de preservativo com o parceiro, querer ou não querer tomar a medicação antirretroviral entre outras condições de vida, saúde e cuidado que possam estar relacionadas à singularidade do usuário que participa do aconselhamento.

Portanto,

. . . ações de aconselhamento realizadas no âmbito dos CTA constituem possibilidade de transformar o cidadão em sujeito de sua própria saúde e de sua doença. $\mathrm{O}$ aconselhamento deve permitir que ele passe a integrar, na sua experiência pessoal, as informações sobre Aids e prevenção, e que encontre alternativas pessoais e coletivas para o enfrentamento das questões propostas pela epidemia (Ministério da Saúde, 1999a, p. 9).

O processo de aconselhamento em DST/ Aids contém três componentes: apoio emocional ao usuário, apoio educativo e avaliação de riscos, que propicia a reflexão sobre valores, atitudes e condutas (Miranda, Barroso, Silva, \& Silva, 2008).

Assim, o aconselhamento constitui-se também como uma ação de prevenção e é componente do processo de diagnóstico, provendo o usuário de atenção individualizada e singular. Sua realização, na prática dos CTA, pode estar presente nos momentos pré e pós testagem e pode não estar restrita ao atendimento das pes- soas que buscam o diagnóstico (Ministério da Saúde, 2010).

$\mathrm{O}$ aconselhamento pode ser oferecido a todos os usuários dos CTA antes da testagem. É neste momento que se realiza o acolhimento, o estabelecimento do vínculo, o levantamento de situações de vulnerabilidade e a orientação sobre o teste. Este é um procedimento que os usuários optam por realizar ou não, independentemente da metodologia diagnóstica utilizada, seja rápida ou convencional. Nesse caso, o profissional acolhe o usuário e dialoga com ele sobre a motivação de fazer o teste, a metodologia a ser utilizada e as expectativas do resultado. O usuário tem o direito de decidir entre as diferentes modalidades de testagem oferecidas pelo CTA (Ministério da Saúde, 2010).

Todas essas ações só atingirão seus objetivos de colocarem o usuário como centro, considerando-o como uma pessoa autônoma, se levarem em conta as conquistas da humanidade na área dos direitos humanos, especialmente dos direitos sexuais. Nessa área de conhecimento, trabalhos têm sido desenvolvidos propondo um modelo operacional para instrumentalizar profissionais de saúde em suas intervenções de prevenção do HIV (Paiva, 1998), e apresentando uma visão alternativa e positiva dos direitos sexuais pautada por princípios éticos e por condições capacitantes que envolvem: a diversidade sexual, as diversas formas de constituição da família, a autonomia para tomar decisões e a equidade de gênero (Petchesky, 1999).

O aconselhamento para revelação do teste de HIV (aconselhamento pós-teste) é um processo no qual profissional e usuário compartilham de uma situação face a face, em que um tem a informação que o outro veio buscar e no qual deve ser oferecido espaço em que se possa depositar o conhecimento que se adquiriu ao longo da vida fazendo as próprias escolhas. $\mathrm{O}$ aconselhador tem uma função constituída como uma espécie de moderador, de emissário da informação que será veiculada, procurando garantir um ambiente de confiabilidade nos resultados, de sigilo e de respeito aos direitos individuais.

Na concepção inicial dos CTAs não estava prevista a criação de vínculos longos e/ou duradouros nos processos de aconselhamento, po- 
rém o número de encontros de atendimentos era aberto. Atualmente, de acordo com a evolução da epidemia e diante da complexidade das situações vivenciadas pelos usuários, tem sido cada vez mais valorizado o vínculo com os usuários. Além disso, é proposto o aconselhamento continuado para pessoas que aguardam os resultados de exames de HIV, sífilis, hepatites e também para pessoas vivendo com HIV/Aids, portadores de hepatites e seus familiares, enquanto não foram encaminhados e atendidos nos serviços de referência para tratamento (Ministério da Saúde, 2010).

A dinâmica do aconselhamento varia muito em função das pessoas envolvidas, mas é desejável que o aconselhador, diante do resultado reagente, esteja capacitado para: (a) oferecer apoio emocional, possibilitando ao usuário tempo para assimilar o impacto do diagnóstico; lidar com sentimentos de culpa, rejeição, punição, desmistificando aspectos de degenerescência, morte, dentre outros; (b) diferenciar a condição de portador do vírus da de doente, informando sobre a necessidade de exames complementares que serão realizados pelo serviço de referência, ressaltando a importância do tratamento para a Aids; (c) reforçar a necessidade de adoção de medidas preventivas para evitar a reinfecção pelo HIV e outras DST, e a transmissão do vírus a outras pessoas; (d) garantir a aprendizagem de como colocar o preservativo; (e) orientar sobre a necessidade de revelar o resultado ao(s) parceiro(s) atual(is), disponibilizando o serviço para isso; e (f) encaminhar para serviços complementares de assistência médica, e social quando necessário, incentivando a adesão à terapia medicamentosa (Ministério da Saúde, 1999a).

Para compreender os processos de aconselhamento analisados neste artigo, foram utilizados conceitos da teoria psicanalítica de D. W. Winnicott. Trata-se de uma teoria que tem como pressuposto que a relação intersubjetiva entre o analista e analisando é o que determina a transformação subjetiva, mais do que cada um dos participantes desta dupla (Winnicott, 1954/1978a).

No desenvolvimento do trabalho analítico o autor propõe a criação de um setting para o atendimento das demandas, que se transformam continuamente na contemporaneidade, exigindo uma mudança de lugar do analista. Em sua concepção, nesse setting, não se prioriza nem o lugar do analista nem o lugar do analisando, recomendando-se uma posição de trânsito entre, um lugar onde o indivíduo possa prover de suas necessidades prementes, sem ser invadido com conteúdos que não consiga suportar, endereçados pelo analista. O lugar proposto é o de uma mãe suficientemente boa que oferece ao seu bebê o holding, isto é, a sustentação da sua angústia fundamental até que ele esteja em condições de utilizar seus próprios recursos e possa caminhar sozinho (Moreno \& Reis, 2002).

Winnicott (1965/1994, 1971/1984), identificando cada vez mais a importância da primeira entrevista em psicanálise, desenvolveu uma modalidade de atendimento denominada consulta terapêutica especialmente direcionada aos indivíduos para os quais não era indicada uma análise nos moldes tradicionais. Caracterizava-se assim, neste(s) encontro(s), uma valorização do tempo e espaço de conversa. Na consulta terapêutica, propõe-se que o ambiente criado facilite a apresentação de questões trazidas pelo sujeito, havendo a sustentação e a gradativa apropriação elucidativa das mesmas por meio da mutualidade. Esse ambiente entre analista e analisando é concebido a partir das noções desenvolvidas a partir da relação mãe-bebê. A mãe, de uma forma especial, introduz o bebê em seus relacionamentos com pessoas e objetos gradativamente, e na medida da sua possibilidade (Winnicott, 1951/1978b, 1971/1975b). A mãe sustenta o bebê ao mesmo tempo em que se adapta às suas necessidades psíquicas, no decorrer de seu processo de amadurecimento. Ela está, com isso, constituindo o holding do bebê, uma noção que é representativa da própria sustentação. Significa que toda a atenção da mãe se volta para o bebê, com uma preocupação que a aproxima de um modo que possa lhe fornecer as provisões egoicas necessárias e que serão fundamentais ao longo de seu desenvolvimento. O holding é traduzido na relação terapêutica como o setting, isto é, um ambiente confiável e de suporte. Assim, transferindo a imagem mãe-bebê para o setting analítico, e, por derivação, para o ambiente existente em uma relação de confiança, apoio e 
ajuda, é esta função exercida como uma "presença sustentadora" que se considera necessária no momento de aconselhamento para revelação do teste anti-HIV.

Winnicott (1986/2001) considera que só se pode verdadeiramente ajudar alguém, quando o interesse pelo que este fala mantém-se vivo. E é esse interesse no usuário que vem buscar o resultado do exame anti-HIV que se procurou investigar nos processos de aconselhamento dos sujeitos ouvidos na pesquisa que originou o presente artigo.

\section{Método}

A pesquisa foi desenvolvida em dois Centros de Testagem e Aconselhamento em DST/ Aids do Município de São Paulo (CTA), serviços onde a tecnologia do aconselhamento é praticada para revelação do resultado do teste anti-HIV. No período da realização da pesquisa o teste sorológico utilizado para detecção da infecção pelo HIV era o Ensaio Imunoenzimático, conhecido como Elisa, cujos resultados eram revelados ao usuário cerca de quinze dias após a sua realização. Quando o resultado era reagente, eram realizados os testes confirmatórios Western Blot ou Imunoblot. Naquele momento não estava disponível, ainda, o teste rápido atualmente empregado nestes serviços para detecção da infecção pelo HIV.

Os dois CTAs possuíam características semelhantes quanto ao horário de funcionamento $\mathrm{e}$ quanto à composição da equipe. Todos os aconselhadores eram do sexo feminino e a formação profissional era variável. Havia médicas, enfermeiras, assistentes sociais, psicólogas e educadoras de saúde pública.

As instituições foram informadas sobre os objetivos e procedimentos do estudo em reuniões com os aconselhadores e a coordenação, previamente à coleta dos dados. Nestes encontros houve concordância quanto à estratégia de indicação de voluntários e quanto à operacionalização da entrevista de coleta de dados, de modo a interferir o menos possível na rotina dos profissionais.

A escolha destas unidades de saúde baseou-se nos seus dados de produção. Dentre os CTAs, estes eram os que mais realizavam testes soroló- gicos anti-HIV no município, por estarem situados em locais de grande circulação de pessoas.

Para a captação de usuários foram afixados cartazes e disponibilizados cartões-convite para serem distribuídos pelas próprias aconselhadoras ao final de cada aconselhamento.

Uma das equipes preferiu abrir um agendamento para entrevistas, com horários prefixados com a pesquisadora, a qual seria avisada quando houvesse usuário interessado em participar da pesquisa. A outra equipe preferiu orientar o usuário a fazer ele mesmo o contato com a pesquisadora para marcar o horário da entrevista. Esse modo de captação não teve o resultado esperado, e após alguns meses, foi aberto nesta unidade um agendamento, a exemplo do trabalho já em andamento no outro CTA. Além desta estratégia de captação, a pesquisadora passou a comparecer no CTA em datas e horários combinados com a equipe, independentemente de haverem voluntários agendados. Essa medida de aproximação da instituição tornou possível tomar depoimentos dos usuários logo após o aconselhamento, quando estavam disponíveis; ou agendar para outro dia, conforme eles desejassem.

Três depoimentos foram tomados antes da revelação da segunda sorologia (exame confirmatório). Observou-se, nesses casos, que os usuários conseguiram expressar suas percepções sobre o modo como thes foi comunicado o resultado, porém dois deles tinham a esperança de que o resultado da segunda amostra de sangue fosse negativo. Um desses entrevistados retornou para a segunda entrevista e foi possível obter informações a respeito dos dois processos de revelação de resultado vivenciados.

Outros três entrevistados foram ouvidos no mesmo dia da segunda comunicação da sorologia e, nos três casos, esse tempo não pareceu interferir na maneira pela qual eles formularam seus depoimentos.

Utilizou-se a técnica da entrevista aberta, definida como "conversa a dois, feita por iniciativa do entrevistador, destinada a fornecer informações pertinentes para um objeto de pesquisa, e centrada (pelo entrevistador) em temas igualmente pertinentes com vistas a este objetivo" (Kahn \& Cannel, 1962, p. 52 citados por Minayo, 1994, p. 108). 
Por meio da frase: "Conte-me, como foi a comunicação do resultado positivo para você aqui no CTA" cada entrevista era iniciada para que a conversa circulasse em torno do aconselhamento, momento no qual o resultado do teste sorológico anti-HIV reagente era revelado.

A partir dessa indicação, criava-se um espaço livre para o sujeito construir a narrativa à sua própria maneira. A entrevistadora introduzia questões quando necessário para favorecer obtenção das informações em torno dos objetivos da pesquisa. Essas questões seguiam tópicos a serem abordados, mas sem roteiro previamente estabelecido. $\mathrm{O}$ usuário podia falar livremente sobre o assunto em foco, como no procedimento denominado depoimento pessoal, história de vida tópica ou história oral (Minayo, 1994; Queiroz, 1991). O usuário era convidado a falar a respeito desta faixa de tempo vivido, que o remetia ao acontecimento ocorrido naquele momento da vida dele e que era o objeto da investigação: a revelação do diagnóstico da infecção pelo HIV.

A utilização da entrevista visou trazer à tona o enredo deste momento repleto de significações, dificilmente acessíveis e compartilháveis, e que têm interferências subjetivas na narrativa do entrevistado, decorrentes de sua memória, de sua vivência da situação e da abordagem da entrevistadora. $\mathrm{O}$ sujeito organizava a sequência e conteúdo de seu relato da forma como ele preferia, podendo realizar idas e vindas, paradas, repetições, além de deixar lacunas decorrentes de falhas de memória, motivação e/ou percepção. Esses aspectos foram importantes para revelar sentimentos ou representações mentais de cada um dos sujeitos ao vivenciar a experiência de revelação do seu diagnóstico da infecção pelo HIV, e de como ele percebeu o aconselhamento do qual participou.

O papel da pesquisadora foi também determinante da continuidade (ou não) nos temas relacionados ao contexto da revelação do diagnóstico, uma vez que, dependendo da condição singular de cada entrevistado, o caminho trilhado pelas narrativas podia se diversificar e se afastar do foco central de interesse do presente estudo. A atitude de escuta da pesquisadora e disponibilidade em um momento subsequente ao aconselhamento foi favorável ao aparecimen- to de conteúdos psicológicos significativos para os usuários. O clima das entrevistas foi sempre descontraído, de forma a permitir a livre expressão dos entrevistados e o trabalho só era encerrado quando o entrevistado dizia que não havia mais informações a acrescentar. A duração das entrevistas variou de 45 minutos a uma hora e 15 minutos.

As entrevistas foram gravadas e transcritas a fim de ". . . manter ao máximo as próprias expressões dos informantes e a sua maneira de encadear os fatos ..." (Queiroz, 1991, pp. 60-61).

Ao final do primeiro encontro com o voluntário, sempre era proposta uma segunda entrevista, deixando claro sua livre escolha para participar ou não. Houve desistências de oito pessoas na primeira entrevista, havendo duas mulheres nesse grupo. Estas pessoas marcaram o horário e não compareceram ou cancelaram antes.

Os critérios de inclusão na pesquisa foram: (a) ter 18 anos ou mais; (b) ter resultado reagente no teste sorológico Ensaio Imunoenzimático (teste Elisa) e exame confirmatório Whestern Blot ou Imunoblot; (c) ter participado do processo de revelação do diagnóstico da infecção pelo HIV nos CTA pesquisados; e (d) ter assinado voluntariamente o Termo de Consentimento Livre e Esclarecido.

$\mathrm{O}$ número de sujeitos de pesquisa não foi definido a priori. O estabelecimento do limite de voluntários se deu em função de critérios como: a dificuldade de captação de voluntários e a consequente demanda e extensão do tempo de coleta em quatro vezes o inicialmente previsto, a repetição dos conteúdos em um mesmo serviço, a qualidade dos dados obtidos a partir das entrevistas e a natureza qualitativa do estudo. O número de pessoas incluídas foi o mesmo nos dois CTAs.

Foram realizadas 20 entrevistas, com 14 sujeitos. O intervalo entre o primeiro aconselhamento e a entrevista variou em função do tempo que cada usuário levou para buscar o resultado. $\mathrm{O}$ intervalo entre a primeira e a segunda entrevista da pesquisa oscilou entre uma e duas semanas, de acordo com a conveniência do sujeito para realizá-la. Dentre os voluntários, oito não compareceram à segunda entrevista. $\mathrm{O}$ tempo despendido para a coleta de dados foi de um ano (entre as datas da primeira e da última entrevista). 
Para a análise das entrevistas, cada uma delas foi considerada como uma unidade de significação dentro do corpus, definido como o conjunto de documentos a serem submetidos aos procedimentos analíticos (Bardin, 1977/1995).

A análise foi precedida por um exame cuidadoso de cada entrevista, tomando-a como um todo, e buscando compreender sua lógica, aspectos ambíguos, contraditórios e inconscientes, a fim de capturar cada história de revelação do diagnóstico da infecção pelo HIV das pessoas entrevistadas.

Para a sistematização e organização dos dados, utilizou-se a técnica de análise de conteúdo, fazendo recortes nos relatos, norteados pelas categorias analíticas construídas a partir dos objetivos da pesquisa. Esses objetivos basearam-se nos aspectos essenciais que devem constar, por definição, no aconselhamento sorológico, conforme normatização do Programa Nacional de DST/Aids. Desse modo foi constituído o corpus.

O que serviu de guia à leitura das entrevistas e organização dos resultados foi o fato de os serviços seguirem o mesmo protocolo e as mesmas diretrizes para o aconselhamento.

A utilização dos conceitos extraídos da teoria de Winnicott, sobre os quais foi estruturado o presente estudo, serviu como ferramenta de interpretação e matriz de análise, cuja construção provém da interação entre as hipóteses iniciais do trabalho e o corpus (Blanchet, 1992), constantemente vistos, revistos e articulados. A interação constante possibilitou operar com os conceitos utilizados fora de seu campo original.

O projeto de pesquisa foi submetido e aprovado pelos Comitês de Ética em Pesquisa da Faculdade de Saúde da Universidade de São Paulo e Secretaria Municipal da Saúde de São Paulo (CAAE 074/2003).

\section{Resultados e Discussão}

\section{Sujeitos de Pesquisa}

Todos os entrevistados eram do sexo masculino, com idade variando de 21 a 65 anos. A escolaridade predominante foi de 8 a 11 anos de estudos concluídos, seguida de 12 ou mais anos de estudo. Apenas um entrevistado referiu ter entre 1 a 3 anos de estudos concluídos. A categoria de exposição à infecção pelo HIV foi a sexual, sendo que a maioria dos entrevistados tinha orientação sexual homossexual. Dois entrevistados foram identificados como tendo orientação sexual heterossexual. A maior parte dos entrevistados tinha parceria fixa no momento da pesquisa, mas apenas três tiveram um ou nenhum parceiro no último ano. Os demais tiveram mais de dois parceiros no último ano, chegando a ter mais de cem parceiros um profissional do sexo.

\section{Análise de Conteúdo e Interpretação}

A elaboração dos resultados foi baseada na construção das categorias que se relacionam aos objetivos da pesquisa. O material empírico será apresentado na medida em que se mostrar relevante para ilustrar a análise e para servir de elemento para a compreensão dos processos de revelação de resultado vividos.

A primeira categoria sintetiza a investigação a respeito da escuta do usuário e de sua centralidade no processo de revelação do diagnóstico do HIV.

A análise dos relatos mostrou que os usuários se dividiram em dois grupos que correspondem grosseiramente às respostas afirmativas ou negativas à questão analisada. Assim, dois deles (Paulo e Omar) manifestaram explicitamente sua opinião negativa em relação à questão envolvida: não se sentiram centro da comunicação, nem se sentiram escutados quanto aos seus sentimentos e preocupações decorrentes da revelação de seu resultado reagente. Os outros doze restantes consideraram que este objetivo foi alcançado na revelação do seu resultado reagente, sendo ouvidos e reconhecidos como estando colocados no centro da conversa. São eles: Sílvio, Milton, Nei, Luís, Juvenal, Evandro, Arnaldo, Mário, Pedro, Cássio, Bruno e Jonas, cujos nomes são fictícios.

Embora tenham considerado terem tido um aconselhamento satisfatório, nota-se em suas narrativas que nem todos conseguiram colocar questões às aconselhadoras por timidez, por serem todas mulheres ou por não se sentirem com direito de ocupar o tempo da profissional:

$E$, eu acho que o homem com a mulher, quando vem um homem tímido, ele vai ter 
vergonha de conversar com a mulher. Acho que, com um homem, ele não tem tanta vergonha, que vai ser homem com homem, né? $A i$, vai, talvez, perguntar mais coisas, porque é homem. Agora com uma mulher, o homem, ele pode ter vergonha de uma mulher. Como tem homem que tem, né? . . com um determinado tempo é que eu posso entrar pra perguntar mais coisas que a gente tem que perguntar. . . Primeira vez que vem ... nem acha a pergunta pra perguntar. Então ele pergunta algumas coisas, de dez ele vai perguntar duas. Entendeu? . . é que a gente acha que o espaço é curto e se vai ficar fazendo perguntas vai demorar demais. Então fica tudo isso na cabeça da gente, né: "não, se eu for fazer muitas perguntas eu vou estar atrapalhando elas." (Sílvio)

Identificaram-se preocupações voltadas ao "daqui para frente", para as manifestações da doença e para algo que os usuários ainda não compreendiam naquele momento. Uma parte dos entrevistados não acreditou de pronto no resultado e necessitaram de um tempo para aceitarem a ideia de estarem infectados pelo HIV, utilizando-se do mecanismo de negação e de racionalização. Ambos os mecanismos de defesa só puderam ser acessados pelos entrevistados, quando houve acolhida e suporte por parte das aconselhadoras.

Outro tipo de negação que surgiu relacionase à dificuldade de aceitar como via de infecção a exposição a uma situação de risco sexual. Um entrevistado insistiu que contraiu o vírus por ter compartilhado um objeto perfurocortante de uso pessoal com um amigo (Evandro). Pelos dados fornecidos por ele próprio, isso não seria possível e o que estava subjacente a essa negativa era sua dificuldade de assumir a orientação sexual homossexual, como foi explorado em seu aconselhamento.

Dentre os sentimentos relatados, foi frequente o medo de ter que depender dos outros, das pessoas com as quais conviviam, e de virem a ser abandonados por elas (Luís e Paulo).

Mesmo tendo espaço de conversa estabelecido, a transferência para outro serviço foi um dos motivos que interrompeu a discussão de questões dos usuários nos aconselhamentos:
"Tive vontade de falar com alguém sobre o que está acontecendo, mas não houve tempo hábil, porque eu já estou indo ao SAE [Serviço de Atenção Especializada em DST/Aids]" (Milton). . . . ela falou sobre esse lugar que ela me passou, que lá vai ter psicólogo. Então... se eu quiser conversar com uma psicóloga, eles oferece lá ... o serviço aqui, o básico é só isso. (Luís)

O espaço aberto para a conversa no aconselhamento e o cuidado para revelar o resultado reagente permitiram aos sujeitos colocações de questões, como as descritas a seguir.

No caso de Evandro, ficou evidente a negação de sua condição de portador de uma doença incurável, por considerar sua infecção pelo HIV passível de cura. Este usuário encontrava-se, também, em um processo de negação da própria homossexualidade. Mas em seu processo de aconselhamento sentiu-se o centro da conversa, tendo seu lugar preservado e respeitado em suas crenças.

Diferentemente de Evandro, Juvenal aceitou sua soropositividade como um fato que não seria negado. E, de certa maneira, o fez de forma complacente, apesar de não esperar ter se infectado pelo HIV e de não fazer sexo seguro sempre.

Pedro assumiu inteiramente a sua falta de proteção frente ao HIV em sua última experiência amorosa. Estava ainda muito impactado pela perda do seu companheiro. Requereu boa parte do tempo da entrevista para falar disso.

O relato de Jonas apontou que, apesar da abertura de espaço, no contato intersubjetivo transpareceu um limite muito tênue entre o cuidado e a repreensão. Explicitou que tendo tido uma quinzena de resultados não reagentes anteriormente, sentiu que a aconselhadora ficou frustrada pela falta da prática da prevenção que ocasionou a infecção pelo HIV. Felizmente, no seu caso, parece ter sido possível esclarecer isso pelo diálogo. Depois que "caiu a ficha" ele pôde se responsabilizar pela sua não prevenção (ou vacilo, como ele diz), porque houve tempo para isso e ele pôde dizer como estava se sentindo:

Foi meio severo assim. Acho que ela pisou, não que pisou na bola, mas foi muito rígida assim "pô, você tá condenado, mas ao mesmo tempo, você tem chance ainda", 
sabe. Eu achei que foi muito duro, isso. Mas foi aquele momento de tensão, mas que de uma certa forma também abriu minha cabeça pra falar "meu, você tá errado, você tem que assumir que você foi errado e agora, a partir de agora, você tem que estar fazendo diferente". ... Eu me expus. ... Falei o que eu estava sentindo no momento, sem medo. (Jonas)

A cautela para dar o resultado foi uma das características apontadas pelos usuários, bem como a necessidade de se criar um vínculo de confiança. Um dos entrevistados que já tinha familiaridade com o serviço e com a aconselhadora que lhe fez a revelação do diagnóstico da infecção pelo HIV contou que, dias após ter recebido o resultado do teste, veio espontaneamente ao CTA para conversar novamente com a aconselhadora. Desse modo, ele confirmou ter tido espaço para falar com ela sobre o que estava sentindo, baseado na confiança que mediou o aconselhamento. Sentiu-se apoiado e acolhido por ela, especialmente por ser atendido por ela sem ter marcado horário.

Senti muita confiança nela [na aconselhadora] . . . eu tinha que vir aqui só amanhã. Falei: "não, eu vou hoje, que eu quero conversar com a [nome da aconselhadora]. Quero ver o que mais ela tem pra me falar". . . Porque no dia eu não quis conversar muito, eu não tinha como contar pra ela. . . . Nem tava marcado nada. Só pedi pra ela se eu podia falar com ela. . . Ela me atendeu pra gente conversar. Ela está sendo ótima, sabe? . . . eu não tenho ninguém pra dividir isso, entendeu? Ai eu estou conversando com ela. . . . Meu primeiro exame negativo foi ela que me entregou, sabe? A segunda amostra, não. E essa agora que deu positiva, também foi ela. ... Ela me deu o telefone daqui também ... Pra qualquer coisa que eu precisasse. (Bruno)

Omar e Paulo não se sentiram colocados no centro de sua comunicação do resultado. Por essa razão, ficaram impossibilitados de falar com as respectivas aconselhadoras sobre seus sentimentos e preocupações, transmitindo as versões mais negativas do que se processou no momento da revelação do resultado,
$\mathrm{Na}$ entrevista de pesquisa, um dos entrevistados tentou criar diálogos fictícios com a aconselhadora, nos quais imaginava como o usuário pudesse se sentir mais acolhido, mas isso não ocorreu com ele. A relação intersubjetiva vivenciada na atividade de aconselhamento foi impessoal:

. . como eu acho que não houve uma preparação, pra dar a noticia, porque se preocupou em preencher os documentos administrativos que faziam parte do processo, então qualquer pergunta que se fizesse ali em relação ao meu sentimento, ali já não era mais válido. Aliás, não surte nenhum efeito. Entendeu? Por mais que você tente confortar a pessoa, não vai surtir nenhum efeito, né? ... Eu que vou passar a informação pra essa pessoa? Legal. Então vou me colocar no lugar dela. Não tornar a coisa muito seca ou então, é. . . . Mais um! Entendeu? Assim. . . Uma coisa corriqueira. Porque todo dia você faz a mesma coisa, então você acaba perdendo a sensibilidade. $\dot{E}$ isso que eu senti. (Omar)

Essa percepção prejudicou a segunda experiência intersubjetiva ocorrida entre este usuário e aconselhadora que deu o resultado do teste confirmatório. Ele recusou a relação de ajuda proporcionada, apesar da percepção de que se tratava de uma aconselhadora com uma escuta mais centrada no usuário. Sua história e suas questões pessoais não chegaram a ser abordadas.

Na segunda vez que eu fui . . a pessoa que conversou comigo me pareceu ter mais sensibilidade, né? . . então eu senti um pouco mais acolhido, né? Mas eu já sabia do resultado. . . . Ficou uma lacuna, né? Sabe quando fica um vácuo? E aí fiquei pensativo. [Fala como se fosse a aconselhadora] "Tudo bem Omar?". . . "Quê que você está sentindo?". . . Mas, eu não consegui, sabe? É ... Extravasar. (Omar)

O outro entrevistado que teve uma sensação negativa, de "atendimento automático", foi Paulo. Em seu primeiro aconselhamento pós-teste, segundo ele, nem houve preparo para dar o resultado reagente, nem espaço para colocar seus sentimentos e emoções decorrentes dele: 
Minha sensação? De que? Da notícia? . . Bem automática! . . Imagina que você tem o cartão do Banco 24 horas, seu cartão entra e sai. . Ele foi muito rápido! . . Não. .

. Não houve espaço. Esse espaço foi questionado depois, quando eu estava levantando, ai já não, se depois dessa notícia já não houve preparação inicial, por que eu vou querer depois? (Paulo)

Os usuários esperavam obter alívio para o sofrimento que a revelação do diagnóstico provocou neles e, puderam obtê-lo quando os processos de aconselhamentos vivenciados foram centrados neles mesmos como sujeitos de sua própria história de infecção.

Nos relatos dos entrevistados identificou-se que eles não tinham com quem conversar, às vezes, nem com quem morar, com a presença de sentimento de angústia por estarem sós.

Os entrevistados mencionaram também a necessidade de o aconselhador respeitar o direito de cada um, de poder escolher entre ter o resultado revelado com cautela, protelação, após os procedimentos de praxe do serviço; ou, ao contrário, de o mesmo ser dado imediatamente, "sem rodeios", tão logo se adentrasse no espaço de aconselhamento.

De acordo com Winnicott (1951/1978b, 1967/1975a), a noção de espaço encontra-se intimamente ligada à de tempo no que tange aos primeiros contatos com a realidade.

$\mathrm{O}$ processo se inicia desde as primeiras experiências de adaptação do bebê, quando a mãe lhe apresenta os objetos na dosagem adequada, de modo a the dar o suprimento adaptativo. Assim,

. . . a mãe consegue funcionar como um agente adaptativo [que] apresenta o mundo de forma a que o bebê comece com um suprimento da experiência de onipotência [grifo do autor], que constitui o alicerce apropriado para que ele, depois, entre em contato com o princípio da realidade. (Winnicott, 1967/1999, p. 13)

Enquanto o bebê não estiver em condições de tolerar frustrações e conflitos com a realidade, a mãe aguarda, adiando até que isso seja suportável para o bebê. Está implícita aí a noção do autor de "ambiente facilitador".
Transpondo para a situação de revelação do diagnóstico da infecção pelo HIV, o que os usuários mostraram é que a delicadeza da situação requer a presença do aconselhador de modo a aguardar na medida da possibilidade de cada um, ou seja: ele necessitaria funcionar como a mãe suficientemente boa, apresentando os objetos da realidade à medida que percebe que o usuário possa suportar as frustrações. Sua presença é também ausência, para que o usuário possa ir se constituindo como um ser separado e gradativamente mais independente com relação à própria condição de soropositivo.

Com relação a este aspecto, observou-se, ainda, que o resultado da segunda amostra (teste confirmatório) permitiu aos usuários desenvolverem um pouco melhor o processo de elaboração do seu diagnóstico, como uma espécie de função adaptativa. Parte deles tentava ter esperança de que o resultado da segunda amostra (comunicado em um segundo encontro) fosse negativo, mas diante da confirmação da soropositividade, poder ter um espaço compartilhado no qual pudessem ser escutados, ajudou-os a lidar melhor com a angústia e elaboração de planos de tratamento. Os dois fatores (tempo de elaboração e tempo de escuta) parecem ter tido efeito favorável a uma melhor condição psicológica para retornar ao serviço em busca da confirmação do resultado.

Filgueiras e Deslandes (1999) observaram e analisaram aconselhamentos de diversos serviços brasileiros, e obtiveram achados semelhantes aos do presente estudo com relação à atitude de acolhimento e escuta dos aconselhadores. Esta era uma das característica do aconselhamento que se encontrava muitas vezes prejudicada nos serviços investigados por estas autoras.

O enfoque sobre as informações referentes à prevenção das DST/Aids, à adesão à Terapia Antirretroviral (TARV) e ao autocuidado foi dado em todos os aconselhamentos, atendendo às recomendações dos programas de prevenção às DST/Aids. Tais informações visam estimular o indivíduo a cuidar da própria saúde com vistas ao aumento da sobrevida.

A maior parte das questões feitas pelos usuários durante o aconselhamento estava rela- 
cionada aos efeitos causados pelo HIV no organismo e à especificidade dos exames e tratamentos que seriam necessários. Os usuários foram orientados a tirar essas dúvidas no outro serviço de referência com o médico ou outro profissional, conforme o caso, ou a própria aconselhadora as esclareceu no momento do aconselhamento.

Apesar dessas orientações, no entanto, os espaços de interlocução e negociação no processo de aconselhamento ficaram prejudicados por questões de ordem pessoal não explicitadas no momento da revelação do resultado, mas relatadas nas entrevistas e que dificultaram a busca por esclarecimentos. De certa forma, estas barreiras mantêm estas pessoas em seu estado de vulnerabilidade individual, não as instrumentalizando para lidar com a infecção, com a doença, e com o uso de práticas preventivas.

Souza et al. (2008) também identificaram em seu estudo posicionamentos diferenciados dos entrevistados quanto à necessidade ou perspectiva de mudança de suas condições de vulnerabilidade e também em relação à tomada de decisão e construção de uma alternativa preventiva.

No presente estudo houve um entrevistado que sugeriu que as informações adicionais fossem fornecidas por escrito, por meio de folheto educativo. Ele considerou que se a pessoa estivesse muito angustiada, não atentaria para as informações que depois lhe seriam essenciais para o cuidado à saúde.

Essa sugestão foi na mesma direção do que foi normatizado em 2001 para testagem e aconselhamento pelo Centro de Controle de Doenças (CDC) de Atlanta, EUA (Galant, 2004). A partir dessas normas foi elaborado um hand out contendo informações para diminuir o risco de infecção pelo HIV, e recursos disponíveis para atendimento, respeitando a cultura, linguagem, sexo, orientação sexual, idade e nível educacional.

Informações sobre os progressos científicos em direção à cura da doença foram também requisitadas por usuários durante a entrevista de pesquisa, sugerindo que, em seu processo de revelação do diagnóstico, questões referentes a elas não foram formuladas.
“. . com o passar do tempo, vai ter cura? Você acha que tem possibilidade de ter cura, a Aids?" (Nei).

Apesar das dúvidas que poderiam permanecer, os entrevistados referiram ter obtido uma compreensão a respeito da necessidade de se cuidar e também de não transmitir o vírus, estando convictos com relação a isso, sem perder a esperança de um dia existir a cura para a Aids.

Em geral foram abordados, durante a revelação do resultado, conteúdos sobre carga viral, infecção por doenças oportunistas e outras doenças, além do tratamento, mantendo nos sujeitos o interesse pela vida. Conteúdos sobre as práticas sexuais desprotegidas também estiveram presentes nos aconselhamentos, havendo reforço sobre a necessidade de evitar o risco envolvendo estas práticas.

"Eu penso agora em viver; não chorar o leite derramado, tocar a vida pra frente; me cuidar bastante, e evitar passar o vírus". (Luis)

Os usuários receberam, ainda, orientação sobre a necessidade de comparecer ao outro serviço que vai avaliar a sua carga viral e o momento de iniciar tratamento.

... Se eu tenho que ter essa carga, eu vou ter que carregar ela; eu não vou dividi-la com ninguém, entendeu? . . . eu quero ver o resultado disso, como é que está primeiro, pra eu chegar a esse medicamento, e tal. Porque agora vai fazer esses exames pra semana que eu vou passar no médico. Eles já me passaram pra lá é porque lá vai ter mais, entendeu, um avanço maior. (Luís)

De acordo com estes achados, a maneira esclarecida e explicativa dos motivos do encaminhamento pode favorecer a passagem do CTA ao SAE. O encaminhamento para o serviço de referência mais próximo da residência dependeu da anuência dos usuários, pois houve a demonstração de receio pela possibilidade de eles encontrarem ali pessoas de sua vizinhança, ou pessoas conhecidas que pudessem tomar conhecimento do diagnóstico da infecção pelo HIV e passarem a discriminá-los:

É um lugar aberto, tem muita gente vendo a gente. . . . Você fica público; todo mundo vai saber, sua vizinhança e volta aquele 
assunto que eu falei. . . Da discriminação. Porque não é todo mundo que senta perto de um aidético no ônibus e não é todo mundo que toma um gole d'água ou de cerveja no mesmo copo. ... Não é todo mundo que compartilha as mesmas roupas. . . Aqui quando você chega, te chamam pra uma sala e conversam com você. . . você está protegido. E lá ... não tem nenhuma proteção da sua identidade; você está exposto a todos ... (Arnaldo)

Assim, o sigilo e a confidencialidade mostraram-se essenciais na situação de aconselhamento, por ser um direito a ser assegurado e porque o usuário vivencia a partir do momento da revelação do resultado a dificuldade de tornar pública a sua condição soropositiva. É um indicador para que os serviços se dediquem mais ao trabalho direcionado aos sentimentos ligados à construção da identidade dos usuários, que se vê alterada pelo resultado do teste. Essa alteração parece estar diretamente ligada à ameaça de viver situações estigmatizantes, caso sua infecção pelo HIV torne-se conhecida por outras pessoas. Estes sujeitos pareceram estar vivendo (e sofrendo) internamente a própria estigmatização. E receavam que isso se exteriorizasse, ou seja, que outros os estigmatizassem quando conhecessem sua soropositividade.

No momento da entrevista de pesquisa, Evandro e Paulo já haviam entrado em contato com os respectivos serviços de assistência em DST/Aids, os mais próximos de suas residências. Evandro passou por uma equipe de acolhimento e agendou consulta com o médico infectologista. No entanto, Paulo recebeu a informação de que teria que pegar uma senha para ser atendido no primeiro dia, o que o deixou preocupado com o acolhimento na nova unidade e a possibilidade de demora no agendamento da consulta.

A integração entre os serviços e o conhecimento de suas rotinas de atendimento mostrou ser necessária para minimizar esse tipo de preocupação sentida pelo usuário e para melhorar a qualidade da informação no aconselhamento. Com isto, o usuário poderia sentir mais segurança ao sair do CTA, favorecendo a adesão ao tratamento recomendado no seu caso.
Os usuários incomodaram-se com as perguntas feitas no aconselhamento associadas à necessidade de prevenção e oferta de preservativos. Tais procedimentos nem sempre respeitaram a singularidade e o sofrimento do momento, pois nem sempre foram administrados de forma delicada:

...foi perguntado se eu tinha alguma dúvida [sobre prevenção] depois do questionário. Quantos parceiros eu tive nos últimos dez anos. Quantas camisinhas eu queria pegar eu achei isso uma frieza im-pres-sio-nan-te [frisa as sílabas].... Não que o profissional tenha que, não vai se envolver emocionalmente com o paciente, mas quem tá aí, tá muito preparado. Estudou pra isso! Quem tá aqui está acabado, está destroçado . . . não vou me lembrar dos últimos dez anos.

. . De quantas pessoas eu tive, de quantos parceiros fixos ... Quantas camisinhas eu vou pegar . . Eu até falei assim pra pessoa: "ah, dez camisinhas" e ela falou assim: "só isso?" Eu falei: "só". . . . Depois de um resultado desse, na hora . . . é indiferente se eu levar vinte camisinhas ou não pegar. . . Eu só quero saber como eu vou lidar com isso ainda. ... Então, pra mim é indiferente pegar camisinhas lá embaixo. Eu não tenho vida sexual no momento. Por acaso ela tomou conhecimento disso? Zerou tudo! (Paulo)

Diante dessa percepção, o efeito sobre o usuário poderia causar dano no sentido da (não) ativação dos seus recursos internos para o enfrentamento do diagnóstico e do desejo de cuidar da saúde. No entanto Paulo possuía uma boa capacidade defensiva e, além disso, teve a oportunidade do segundo aconselhamento com outra profissional. Esta aconselhadora possibilitou a instauração de uma nova relação de ajuda e de mutualidade. Pode-se também dizer que esta aconselhadora permitiu a criação da terceira área, destacada por Winnicott (1967/1975a) como

... uma área da experiência [grifo do autor] no espaço potencial existente entre o indivíduo e o meio ambiente, aquilo que, de início, tanto une como separa o bebê e a mãe, 
quando o amor desta, demonstrado e tornado manifesto como fidedignidade humana, na verdade fornece ao bebê sentimento de confiança no fator ambiental. . . . O espaço potencial entre o bebê e a mãe, entre a criança e a família, entre o indivíduo e a sociedade ou o mundo, depende da experiência que conduz à confiança. Pode ser visto como sagrado para o indivíduo, porque é aí que ele experimenta o viver criativo. (p. 142)

Estendendo para a situação de análise, para o autor, é importante que o analista se dê conta desse lugar de continuidade-contiguidade, que se encontra onde os fenômenos transicionais se originam e se localiza entre ambos (Winnicott, 1967/1975a).

Os outros entrevistados apresentaram-se de modo diferente de Paulo quanto ao encaminhamento, não apresentando mais dúvidas sobre a prevenção e sobre o tratamento, pois foi possível esclarecê-las no espaço do aconselhamento. É o caso de Bruno que pôde relembrar da situação infectante e pôde também expor sua condição de trabalhador do sexo, mesmo tendo apontado que percebe que as pessoas têm preconceito com relação a isso. Esse usuário tinha plena consciência do risco que corria em suas práticas sexuais como trabalhador do sexo, demonstrando poder de negociação e atenção às regras de proteção, mas na relação afetiva se distanciou do saber internalizado, deixando-o "de fora", não o adotando.

Em função da experiência de revelação de Omar ter sido negativa, ele não estava com disponibilidade interna para assimilar mais informações sobre prevenção, Em sua opinião havia um excesso de informações e uma carência de espaço intersubjetivo para sua veiculação.

. . . E esse o resultado! Se eu não tivesse preparado pra receber essa informação, na segunda vez da confirmação, eu não ia participar dessa entrevista [da pesquisa], não ia fazer nada. Por quê? É o sentimento e tudo mais. É muito papel. Você fica assim: “meu Deus!" . . E aí eu sigo aí na rua ai, louco, "faz de conta que não estou com nada". E. . . Ponto final! E vou levar minha vida normal. É esse o intuito? Não é o intuito, não é? (Omar)
O tom de sua fala era de indignação e de protesto contra a forma como foi atendido na situação de aconselhamento do primeiro teste. Essa experiência poderia ter prejudicado a sua participação no estudo que o interessou e ao qual daria sua colaboração. No entanto, Omar mostra que não se fechou totalmente.

Existe uma necessidade de estreitar a ligação entre prevenção e assistência e isso só pode ser iniciado pelo aconselhamento. A qualidade de vínculo e de entendimento é o primeiro passo para isso.

Três dos usuários participariam de outro estudo que dava a garantia de tratamento em um serviço de excelência, mas a primeira indicação feita pela aconselhadora foi de serviço de referência mais perto da residência deles, para onde Jonas se dirigiu inicialmente.

. . sinceramente, eu achei o lugar meio negativo . . o atendimento lá é totalmente precário. Eu vi que não iria me satisfazer como cidadão, sabe. . . Não é porque a pessoa está positiva que ela deve estar naquele tratamento. Acho que as coisas poderiam ser um pouco melhores. Eu acho que poderia ser um pouco mais humano. E eu não me senti bem lá. (Jonas)

Apesar desses pontos negativos assinalados e das diferenças entre os aconselhamentos investigados, todas as narrativas apresentadas mostraram que os aspectos envolvidos nesta categoria de análise foram contemplados, em maior ou menor grau. As dificuldades parecem ter sido decorrentes de vínculo prejudicado entre a aconselhadora e o usuário, e de certo mal-estar provocado pela mudança de instituição assistencial. Embora reconheçam a complexidade requerida na sequência do seu tratamento, a separação de um local de atendimento conhecido e acolhedor para outro desconhecido foi geradora de ansiedade para uma parcela dos entrevistados.

Praticamente todos os entrevistados saíram da situação de aconselhamento com a convicção de continuarem praticando sexo seguro e desejando cuidar da saúde, seja levando uma vida com hábitos saudáveis, seja aderindo ao tratamento a ser recomendado em cada caso. Diante desses dados, pode-se supor que os objetivos analisados de reforçar as práticas preventivas, e 
de incentivar o tratamento e autocuidado foram atingidos de forma satisfatória nos aconselhamentos investigados.

Existem diversas recomendações feitas pelo Programa Nacional de DST/Aids que dizem respeito aos conteúdos que devem ser abordados e que nem sempre é possível tratar de todos na comunicação do resultado reagente. Assim a análise terá como foco quais foram os aspectos privilegiados nos processos de revelação do diagnóstico da infecção pelo HIV descritos no presente artigo.

Aspectos como o preenchimento da ficha epidemiológica, a superação das dificuldades em compartilhar a notícia a outrem e o oferecimento de outro horário de atendimento tiveram seu lugar destacado nos aconselhamentos relatados.

O primeiro, Preenchimento da Ficha Epidemiológica, diz respeito a um procedimento instituído na rotina dos CTA ao qual todos os entrevistados se referiram. Trata-se de perguntas padronizadas com a finalidade de levantar os dados epidemiológicos que são importantes para o conhecimento do perfil da epidemia, a fim de programar ações destinadas ao combate e prevenção da Aids.

Cerca de três entrevistados consideraram desconfortável responder às perguntas, pois tinham que explorar a própria memória. Esse desconforto se associou ao fato de ter que remexer no passado de práticas sexuais (ou de outra ordem) buscando caracterizar situações de exposição ao risco de infecção pelo HIV. Estas indagações provocaram mal-estar nestes entrevistados, como já apontado.

A contabilidade relacionada ao uso de preservativo nas relações sexuais também foi abordada, tanto no que se refere ao uso já acontecido, quanto à oferta de uma quantidade deste insumo para uso nas relações sexuais futuras. Esse último aspecto pareceu fora de tempo e lugar, em função da paralisação ou interrupção de projetos e desejos amorosos naquele momento, como foi o caso de Pedro (impactado, ainda, pela perda do parceiro pela Aids) e Paulo ("zerado" na atividade sexual pela descoberta da soropositividade).

Frequentemente a dinâmica estabelecida nos aconselhamentos e o modo como a aborda- gem das questões era feita causou a impressão nos sujeitos de que a tarefa de preenchimento dos formulários era mais importante do que o reconhecimento dos indivíduos como pessoas. As aconselhadoras funcionaram nestes casos como uma mãe intrusiva, com uma presença invasiva e que não dá permissão ao outro para se colocar (Winnicott, 1954/1978a).

Mesmo reconhecendo os limites do papel desempenhado pelo profissional, é importante identificar a possibilidade de sustentar e acolher a angústia que emerge nesta situação. Esta habilidade é fundamental e não pode faltar ao aconselhador, não para resolver sozinho o problema, mas exercer uma função de depositário da angústia que o outro traz. Trata-se, então, de constituir o holding e um ambiente de provisões envolvendo ambos, não só o aconselhado, mas também o aconselhador, formando a mutualidade. Com isto, o sofrimento pode ser compartilhado e apoiado, não permitindo que um aspecto como a quantidade de preservativos a serem ofertados ocupe lugar privilegiado e nem provoque desamparo e revolta como foi mencionado.

Na mesma direção, outro usuário apontou que o modo como as perguntas foram feitas causou um aumento de sua expectativa e ansiedade com relação ao resultado, e da distância entre a aconselhadora e ele. Ele sentiu que os aspectos formais e burocráticos da instituição tinham mais valor do que o ser humano-usuário, que não parecia ter a subjetividade garantida:

Ela foi anotando alguns dados, tal e aí você fica um pouco naquela apreensão, né? . . . "Já fala logo pra não ficar com rodeios". Embora eu acho que ... pra você dar uma notícia dessa ... eu acho que tira um pouco da parte do administrativo, porque você tá lidando com uma pessoa. Depois que você deu a notícia, enfim, aí você vai cuidar da sua papelada. Entendeu? Sabe fica aquela coisa meio mecânica. Meio não, totalmente mecânica, né? (Omar)

No entanto, nem todos os entrevistados sentiram-se incomodados com o preenchimento do questionário, mesmo considerando difícil relembrar coisas do passado “. . . que você não está mais praticando [e que] você quer é esquecer. . .", como no caso de Evandro. 
Esses relatos mostram que não existe uma única maneira de abordar o mesmo procedimento, uma vez que as pessoas são diferentes umas das outras. O que parece importar é o setting criado e que se inicia desde o momento em que o usuário telefona para marcar o horário de aconselhamento.

Para Winnicott (1968/1994), referindo-se à consulta terapêutica:

A base para este trabalho especializado é a ideia de que um paciente . . trará para a primeira entrevista uma certa capacidade de acreditar [grifo do autor] na obtenção de auxílio e de confiar naquele que o oferece. O que se necessita desse último é um setting estritamente profissional no qual o paciente fique livre para explorar a oportunidade excepcional que a consulta proporciona para a comunicação. (p. 230)

Com base no que foi exposto, a consulta terapêutica é um dispositivo cuja prática produz efeitos terapêuticos nos usuários que dela participam. Considera-se a partir dos achados do presente estudo que esta concepção poderia ser usada no sentido de produzir derivações para os equipamentos de atenção e assistência em saúde coletiva, notadamente no contexto de aconselhamento sorológico. A partir de uma demanda de análise trazida pelo indivíduo, o analista vai conduzir o trabalho analítico. Por existirem demandas por psicoterapia, cujo trabalho está mais voltado para o enfretamento de uma sintomatologia, Winnicott desenvolveu a modalidade da consulta terapêutica. Nestas, o enfoque era relativo às possibilidades de trabalho em relação ao tempo e tipo de problema trazido. Apesar de haver uma diferença fundamental entre esta modalidade e o aconselhamento para revelação do resultado reagente, considera-se que uma aproximação entre as duas abordagem poderia produzir efeitos promissores, tanto para o usuário, quanto para o aconselhador.

O oferecimento de outro horário de atendimento pelo aconselhador foi um aspecto também levantado pelos entrevistados. Essa possibilidade de irem outra(s) vez(es) para conversar, caso precisassem, foi oferecida em ambos os serviços. No entanto, uma minoria fez uso deste oferecimento. Muitas vezes a intenção de voltar estava obliterada pela indicação da continuidade de atendimento em outro serviço para início do tratamento, como ilustra o relato:

Eu até falei: "eu vou pra lá, eu fui encaminhado para lá, mas eu posso visitar vocês de vez em quando?" [A aconselhadora] $\mathrm{Fa}$ lou: "você pode sim, sem problema nenhum. Na hora que você quiser vir, é só marcar um horário". . . (Pedro)

A frase de consentimento da aconselhadora expressa a possibilidade de novos encontros, mas existe uma ambiguidade, uma vez que o usuário já foi colocado a caminho da outra unidade de saúde.

Estas questões denotam a complexidade e a quantidade de informações a serem dadas em um encontro de aconselhamento. Por essa razão podem ser privilegiadas em cada aconselhamento as questões mais pertinentes às necessidades de cada usuário naquele momento, respeitando sua singularidade.

Essas considerações assinalam que o horário adicional pode ser imprescindível para aplacar a angústia da quantidade de informação a ser transmitida, tanto para o aconselhador, quanto para o usuário. Pode-se, ainda, fazer uma reflexão sobre formas para uma melhor efetivação do horário adicional oferecido. $\mathrm{O}$ usuário parece não se engajar, por ficar a meio caminho entre o CTA e o outro local de atendimento. Está em trânsito, ainda não chegou ao seu destino, mas já partiu do lugar de origem.

A superação das dificuldades em compartilhar a noticia a outrem foi uma questão abordada pelos aconselhadores e privilegiada nos aconselhamentos vividos pelos entrevistados.

O tema apareceu de forma diversificada para cada usuário entrevistado. Para Sílvio, Evandro, Cássio e Milton essa era uma questão essencial e preocupante. Não só pelo fato da divulgação da infecção em si, como também pela necessidade de propor aos parceiros que fizessem seu próprio teste anti-HIV.

Para outro (Mário) a dificuldade de quebra do sigilo referia-se à família. A mãe de Mário desconhecia, inclusive, a situação sorológica positiva de seu irmão, anteriormente diagnosticado.

Outros (Paulo, Pedro e Milton) refletiam sobre a pessoa da família mais indicada a quem 
dariam a notícia, pois não tinham proximidade com todos os familiares ou não confiavam em sua compreensão a respeito da doença.

Luís e Juvenal, não tendo família em São Paulo, pensavam em quais seriam as pessoas de sua relação que poderiam se solidarizar com eles.

Por fim, Nei e Luis preocupavam-se com a divulgação da notícia no trabalho. $\mathrm{O}$ temor do preconceito existente e da discriminação que pudesse ocorrer era o sentimento predominante e fator que impedia a comunicação da condição sorológica a terceiros.

O espaço dado para conversar sobre o preconceito e sobre dificuldades envolvidas na revelação de sua condição sorológica variou em função da dupla aconselhador-aconselhado e das dificuldades de escuta e de formação de vínculo já apontadas. Foi também bastante variável a situação de relacionamentos afetivos dos entrevistados, o que determinou a multiplicidade de enfoques e diversidade com respeito às questões levantadas.

No caso de Silvio, o aconselhamento esteve muito centrado em como (e quem) revelar o diagnóstico às parceiras, pelo fato de ele possuir relação estável com duas mulheres ao mesmo tempo. Ele relatou que a ajuda das aconselhadoras foi fundamental para lidar com o problema. Ele levou as duas mulheres ao serviço, uma de cada vez, para fazer o teste:

. . . eu trouxe a primeira, que eu estou com ela agora, que é a mãe dos meus três filhos. Eu trouxe ela. . . . A outra, até agora não sabe. Ela não sabe, eu não tive como ainda falar pra ela, tanto que eu falei com as meninas aqui [as aconselhadoras], se seria mais fácil elas mesmas falar ... porque ela é muito nervosa, né? (Silvio)

E isso foi feito pelas aconselhadoras no CTA. Este entrevistado teve dificuldades de dizer a elas que teve outros relacionamentos fora da relação conjugal com ambas. Por meio de um deles contraiu o HIV. Contar que estava com o vírus significava contar que manteve relações extraconjugais. A revelação do resultado reagente propicia que questões singulares como esta possam ser trabalhadas pelos sujeitos no aconselhamento. Infidelidade revelada passa a ser o maior problema a ser enfrentado para dar essa notícia.
A presença das mulheres para serem comunicadas da positividade do companheiro era uma questão inusitada para o CTA. Apesar disso, ele estava sendo acolhido pela equipe do serviço para tratar das dificuldades familiares decorrentes de sua infecção pelo HIV. As respostas nem sempre estão à disposição, e nem sempre estão prontas. Às vezes é necessária a construção e reconstrução de modos de resolução das questões que se apresentam.

Para contar para a família, um dos sujeitos foi quem mais se angustiou e considerou necessária a abordagem desse tema no processo de aconselhamento:

. . Eu acho não, deve abordar porque . . - quem é a primeira pessoa que eu vou falar isso? "Olha gente, eu sou portador do HIV', entendeu? Mas, assim, eu não quero que se alarde isso. . . . Eu não quero envolver a família, mas tem esse alguém que eu quero comentar, mas como é que eu vou comentar com essa pessoa? ... Isso tem que ser trabalhado, eu acho. Quando eu sair daqui, eu vou sair sozinho, eu sei que eu vou continuar sozinho. Mas às vezes as conversas podem até ajudar um pouco. (Paulo)

Mas mesmo considerando importante falar sobre como revelar a soropositividade a outrem, este entrevistado não teve esta oportunidade em seu aconselhamento:

Negro, pobre, japonês, gente pobre ou não, gente ignorante ou não, tem nivel superior ou não: quem está aqui, está sozinho ... "em quem vou confiar?" . . por isso que eu acho que devia ter esses espaços. . . Não estou te questionando também, se não foi dado. Eu também não perguntei, né, mas é uma coisa que precisa ser analisada. (Paulo)

$\mathrm{O}$ aspecto contar no trabalho adquiriu bastante importância para os entrevistados que sentiram que seu emprego poderia estar ameaçado pela soropositividade de seus testes de HIV. Metade dos usuários estava fora do mercado de trabalho formal e essa questão não se apresentou para eles, como foi o caso de Sílvio, Milton, Evandro, Cássio, Pedro, Mário, Arnaldo e Jonas. Outros se sentiam de certa forma, seguros em relação aos seus respectivos trabalhos, como era o caso de Paulo, Omar, Bruno e Juvenal. No 
entanto, para Nei e Luís, contar o resultado no local de trabalho era uma questão importante por razões diversas:

Um deles (Nei) achava complicado contar no trabalho, em função de trabalhar apenas há três meses e por já ter tido um colega que sofreu preconceito e foi isolado pelos outros por portar o HIV. A possibilidade de ser discriminado e de ser tratado de forma estigmatizante naquele ambiente preocupava-o, mas ele achava que pelo menos seu chefe imediato deveria saber.

O outro entrevistado já havia sofrido muito com o preconceito e a discriminação por ser homossexual. Frequentemente, tinha que enfrentar as pessoas no local de trabalho para se fazer respeitar. Enfrentava, ainda, problemas trabalhistas ligados a acidentes de trabalho que ainda não estavam devidamente resolvidos junto à previdência social. Em seu aconselhamento foi mencionada a possibilidade de procurar a assistente social do serviço de referência para orientá-lo quanto aos seus direitos por ser portador da doença. Isso foi importante porque ofereceu a ele um caminho possível para resolver seu conflito. Não obstante, tinha muitas inquietações com relação ao trabalho:

. . . o homem que é homossexual, ele já é manjado, já é criticado e com a doença, que o meu medo é dentro da firma porque eu já fui muito criticado ... eu, falar eu não vou, dentro da empresa, e também se falar . . a ai vai ser uma coisa que vai complicar. "Além de viado, tá com Aids". . . . Isso é que na minha cabeça tá, aquilo assim, entendeu? ...E agora com uma notícia dessa, se cai na boca deles... Então eu acho que em casa, eu vou, depois desse resultado com a assistente social, eu vou ver. . . Se eu ficar ganhando o mesmo salário, eu prefiro mais ficar na minha casa e trabalhar de camelô. (Luis)

Analisando os relatos com o uso da teoria de Winnicott (1965/1994, 1971/1975b, 1986/2001), pode-se considerar que quando o setting é constituído de modo a sustentar a angústia do sujeito em aconselhamento, torna-se possível agir com naturalidade e mais do que isso, trazer à tona a história e constituição psíquica de cada um. Pode ser ainda viável aos sujeitos usarem os próprios mecanismos (negação, projeção, racionalização, dentre outros) já desenvolvidos como parte dos recursos egoicos. Esses mecanismos podem ser acessados para que eles possam se defender do horror que a situação às vezes provoca, mesmo que eles considerem ser esta uma consequência das práticas que eles tiveram na vida.

Em termos winnicottianos, esta situação pode ser considerada como um trauma, entendido como quebra da continuidade da existência, que de certa forma interfere no caminho da dependência rumo à independência do indivíduo. A continuidade do Ser será possibilitada pela criação de um ambiente facilitador que permita a reconstrução dos aspectos danificados.

Assim, para que o setting seja constituído desta forma "suportiva", é preciso que determinadas funções do ambiente permitam a colocação em marcha dos recursos do psiquismo. $\mathrm{O}$ sujeito os possui, mas ele precisa ter a chance para utilizá-lo no processo de elaboração de sentimentos e de resolução dos conflitos que se apresentam naquele momento. Isso se efetivou nos aconselhamentos investigados em que a presença da aconselhadora permitiu que os usuários "a usassem". Essa é uma expressão winnicottiana que significa: fornecer suprimento adaptativo de provisões para que o indivíduo tenha tempo de se recuperar e possa usar as suas próprias.

Até mesmo a entrevista padronizada (coleta de dados epidemiológicos), que para uma parte dos entrevistados foi insuportável de aturar, para outros foi como parte do holding. De acordo com a psicanálise winnicottiana pode-se sugerir, como explicação, que o manejo da situação possibilitou e criou essa condição de holding. O holding proporcionou a esses usuários entrar em contato aos poucos com o real da notícia. Os mecanismos defensivos apontados funcionaram por um período de tempo, somente o necessário. Se usados excessivamente, estes mecanismos poderiam criar a falsidade, uma espécie de máscara para evitar o sofrimento pelo resultado tão temido (mas já sabido). Eles foram deixando de agir quando cada usuário que vivenciou a experiência de suporte já podia tolerar a realidade com a ajuda da aconselhadora, e do que ela representou para eles. 


\section{Conclusão}

A maioria dos entrevistados sentiu que houve disponibilidade por parte das aconselhadoras no momento de revelação de sua sorologia reagente, a partir da qual puderam vivenciar uma relação de proximidade, compartilhamento e cuidado. Sob essa condição, puderam falar de suas preocupações e serem ouvidos, recebendo o suporte necessário e podendo dar sentido e significado a experiências relacionadas a terem se infectado pelo Vírus da Imunodeficiência Humana. Essa possibilidade lhes permitiu a compreensão e transformação de questões que trouxeram e que colocaram em movimento suas emoções e preocupações sentidas naquele momento. Nesses casos, portanto, tendo sido possibilitado o tempo e espaço para a escuta, defesas foram se enfraquecendo e a realidade se apresentando mais e mais, podendo revelar os verdadeiros sentimentos, principalmente relacionados à perda da condição de integridade do sistema imunológico.

Em contrapartida, para dois entrevistados, não foi possível o desenvolvimento completo de uma experiência de escuta de seus sentimentos e preocupações. No seu processo de aconselhamento não houve a oportunidade de uma escuta suficiente para possibilitar a ativação de seus recursos psicológicos, a fim de poderem sustentar suas manifestações afetivas diante da revelação do resultado do seu teste anti-HIV reagente. Assim, nem sempre a aconselhadora funcionou como a mãe suficientemente boa winnicottiana, proporcionando o espaço e tempo suficiente para uma vivência compartilhada de mutualidade, suporte e ajuda.

Em resumo, na maior parte dos aconselhamentos investigados houve a criação de um ambiente adequado e acolhedor, provendo os usuários de suprimento adaptativo, em outros não. Ou seja: o aconselhamento praticado nos serviços investigados funcionou bem para uns, quando levado a cabo em toda a sua amplitude de escuta, permitindo com isso, a ativação dos recursos psicológicos dos sujeitos e efetivamente dando o apoio emocional necessário naquele momento. Todavia, não foi favorável para outros, quando simplesmente seguiu sua normatividade, abolindo a escuta singular e o compartilhamento que possibilita a vivência transicional no processo de aconselhamento para revelação do diagnóstico da infecção pelo HIV. Ou seja, nestes casos não foi possível aos sujeitos envolvidos obterem o apoio emocional necessário para sustentação de seu sofrimento diante da revelação do diagnóstico da infecção pelo HIV.

Assim, pode-se concluir que no aconselhamento, quando os profissionais possibilitam espaço para que cada sujeito singular apresente sua própria história e sua demanda, eles podem fazer uma boa escuta e podem oferecer o apoio emocional necessário naquele momento e a empatia é a condição necessária ao alcance disso. $\mathrm{Na}$ versão dos usuários entrevistados as aconselhadoras só puderam se aproximar dos seus sentimentos e percepções com relação ao resultado do teste para oferecer suporte, quando tiveram a capacidade de se colocar no lugar deles e de interagirem com eles levando em conta seus pontos de vista diante daquele resultado. Desse modo, o aconselhamento sorológico pode se revelar como uma tecnologia de ajuda que possibilita ao usuário: (a) lidar com o sofrimento psíquico que o resultado reagente do teste anti-HIV mobiliza; (b) ter a chance de falar de suas angústias; (c) superar as dificuldades em compartilhar a notícia com parceiros e familiares, e (d) tirar dúvidas sobre prevenção de DST e HIV. Todos esses são componentes que devem estar presentes nos processos de testagem e aconselhamento em DST/Aids.

\section{Referências}

Bardin, L. (1995). Análise de conteúdo. Lisboa, Portugal: Edições 70. (Trabalho original publicado em 1977)

Blanchet, A. (1992). L'enquête et les methodes: l'entretien. Paris, France: Nathan.

Filgueiras, S. L., \& Deslandes, S. F. (1999). Avaliação das ações de aconselhamento: Análise de uma perspectiva de prevenção centrada na pessoa. Cadernos de Saúde Pública, 15(2), 121131. Recuperado em 13 abril de 2003, de http:// www.scielo.br/scielo.php

Galant, J. E. (2004). HIV counseling, testing and referral. American Family Physician, 70(2), 295302. 
Minayo, M. C. S. (1994). O desafio do conhecimento: Pesquisa qualitativa em saúde (3. ed.). São Paulo, SP: Hucitec.

Ministério da Saúde. (1999a). Diretrizes dos Centros de Testagem e Aconselhamento (CTA): Manual. Brasília, DF: Autor.

Ministério da Saúde. (1999b). Aconselhamento em DST, HIV e AIDS: Diretrizes e procedimentos básicos. Brasília, DF: Autor.

Ministério da Saúde. (2010). Diretrizes para organização e funcionamento dos CTA do Brasil. Brasília, DF: Autor.

Miranda, K. C. L., Barroso, M. G. T., Silva, L. M. S. da, \& Silva, M. R. F. da (2008). Reflexões sobre o aconselhamento em HIV/AIDS em uma perspectiva freireana. Revista Brasileira de Enfermagem, 61(6), 899-903.

Moreno, D. M. F. C., \& Reis, A. O. A. (2002). O momento da comunicação do resultado sorológico para o HIV sob a ótica winnicottiana. Pulsional: Revista de Psicanálise, 156, 20-25.

Paiva, V. (1998). O sujeito sexual: Uma proposta de intervenção. Sexualidade, Gênero e Sociedade, 1(10), 4-8.

Petchesky, R. P. (1999). Direitos sexuais: Um novo conceito na prática política internacional. In $\mathrm{R}$. Barbosa \& R. Parker (Orgs.), Sexualidades pelo avesso: Direitos, identidades e poder (pp. 1538). Rio de Janeiro, RJ: Editora 34.

Queiroz, M. I. P. (1991). Variações sobre a técnica do gravador no registro da informação viva. São Paulo, SP: T. A. Queiroz.

Rogers, C. (1974a). Antigas e novas perspectivas sobre a consulta psicológica e a psicoterapia. In C. Rogers (Org.), Psicoterapia e consulta psicológica (pp. 30-58). Lisboa, Portugal: Moraes.

Rogers, C. (1974b). O lugar da consulta psicológica. In C. Rogers (Org.), Psicoterapia e consulta psicológica (pp. 15-29). Lisboa, Portugal: Moraes.

Souza, V. de, Czeresnia, D., \& Natividade, C. (2008). Aconselhamento na prevenção do HIV: Olhar dos usuários de um centro de testagem. Cadernos de Saúde Pública, 24(7), 1536-1544.

Winnicott, D. W. (1975a). A localização da experiência cultural. In D. W. Winnicott, $O$ brincar e a realidade (pp. 133-145). Rio de Janeiro, RJ: Imago. (Trabalho original publicado em 1967)
Winnicott, D. W. (1975b). O brincar e a realidade. Rio de Janeiro, RJ: Imago. (Trabalho original publicado em 1971)

Winnicott, D. W (1978a). Aspectos clínicos e metapsicológicos da regressão no setting psicanalítico. In D. W. Winnicott, Textos selecionados: Da Pediatria à Psicanálise (pp. 459-481). Rio de Janeiro, RJ: Francisco Alves. (Trabalho original publicado em 1954)

Winnicott, D. W. (1978b). Objetos transicionais e fenômenos transicionais. In D. W. Winnicott, Textos selecionados: Da Pediatria à Psicanálise (pp. 389-408). Rio de Janeiro, RJ: Francisco Alves. (Trabalho original publicado em 1951)

Winnicott, D. W. (1984). Consultas terapêuticas em Psiquiatria Infantil [Therapeutic consultations in child psychiatry] (J. M. X. Cunha, Trad.). Rio de Janeiro, RJ: Imago. (Trabalho original publicado em 1971)

Winnicott, D. W. (1994). O jogo do rabisco. In C. Winnicott, R. Shepherd, \& M. Davis (Orgs.), Explorações psicanalíticas (pp. 230-243). Porto Alegre, RS: Artes Médicas. (Trabalho original publicado em 1968)

Winnicott, D. W. (1994). O valor da consulta terapêutica. In C. Winnicott, R. Shepherd, \& M. Davis (Orgs.), Explorações psicanalíticas (pp. 244248). Porto Alegre, RS: Artes Médicas. (Trabalho original publicado em 1965)

Winnicott, D. W. (1999). O conceito de indivíduo saudável. In D. W. Winnicott, Tudo começa em casa (pp. 3-22). São Paulo, SP: Martins Fontes. (Trabalho original publicado em 1967)

Winnicott, D. W. (2001). Holding e interpretação [Holding and interpretation] (S. M. T. M. Barros, Trad., 2. ed.). São Paulo, SP: Martins Fontes. (Trabalho original publicado em 1986) 